http:/ / dx.doi.org/10.21707/gs.v11.n02a015

\title{
Manejo, ASPECtos SANitários E QUALIDAdE dA ÁGUA DE CISTERNAS EM COMUNIDADES DO SEMIÁRIDO SERGIPANO
}

\author{
Gilsia Fabiane Oliveira Morais ${ }^{1}$, Nataly Albuquerque dos Santos ${ }^{2}$, Anderson Nascimento do \\ VASCo $^{1 *}$, Fábio Brandão Britto ${ }^{1}$
}

\author{
${ }^{1}$ Instituto Federal de Sergipe \\ ${ }^{2}$ Docente do Departamento de Tecnologia de Produção de Origem Animal- CTDR/ UFPB. Professora do Programa de Pós Graduação em Meio Ambiente \\ e Desenvolvimento (PRODEMA/ UFPB). Universidade Federal da Paraíba \\ *Autorpara correspondência: anderovasco@yahoo.com.br
}

Recebido em 18 de março de 2016. Aceito em 26 de novembro de 2017. Publicado em 29 de julho de 2017.

REsumo - Em regiões semiáridas do Brasil as tecnologias de captação de água da chuva auxiliam no suprimento para consumo humano de várias famílias, principalmente nos meses de estiagem. Para conhecer esta realidade, a pesquisa foi desenvolvida em comunidades rurais dos municípios de Simão Dias e Tobias Barreto, em Sergipe, com o objetivo de avaliar as formas de manejo e qualidade da água armazenada em cisternas domiciliares. A metodologia adotada foi do tipo qualitativa e exploratória, desenvolvida com a aplicação de 44 formulários para o diagnóstico socioambiental das famílias e coleta de 44 amostras de água armazenada nas cisternas para análise microbiológica em laboratório. Os resultados das amostras de água revelaram contaminação microbiológica por coliformes totais em todas as cisternas de ambos os municípios e por Escherichia coli em 100\% dos domićlíos de Tobias Barreto e 75\% dos de Simão Dias. O comprometimento sanitário da água possivelmente está relacionado às deficiências na manutenção e conservação do sistema de captação e armazenamento de água como telhados, calhas, dutos e cisterna; e ao manejo dos usuários na retirada da água das cisternas, no qual predomina o uso de baldes presos em cordas. As médias de Coliformes Totais e E. coli nos períodos chuvoso e seco, analisadas pelo método estatístico teste T, mostraram significância estatística na contaminação da água nos períodos de coleta nos dois municípios. A capacitação e mobilização dos beneficiários são aspectos centrais para melhor qualidade da água, minimizar possíveis riscos à saúde e garantir correto funcionamento destes sistemas.

Palavras-Chave: Água de Chuva; Controle Microbiológico; Coliformes; Semiárido.

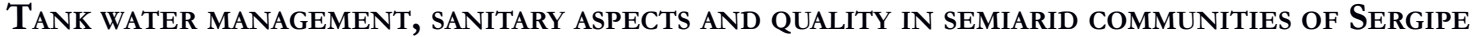

ABstraCt - In semiarid regions of Brazil, rainwater-collecting technologies help supply water to several families for human consumption, especially during the dryseason. In order to understand this reality, the research was carried out in rural communities of Simão Dias and Tobias Barreto counties, in Sergipe, with the objective of evaluating the management and quality of water stored in cisterns. A qualitative and exploratory methodology was adopted, developed with the application of 44 forms for the families' socioenvironmental diagnosis and the collection of 44 samples of water stored in the cisterns for microbiological analysis in the laboratory. The results of the water samples revealed microbiological contamination by total coliforms in all cisterns iof both counties and by Eschericbia coli in 100\% of Tobias Barreto households and $75 \%$ of those of Simão Dias. The possible reason for the sanitary failingof the wateris themaintenance deficiencies and conservation of the water capture and storage system, such as roofs, gutters, ducts and cistern; And due to the users in the removal of water from the cisterns, where the use of buckets attached to ropes is predominant. The mean values of total coliforms and E. coli in the rainy and dry periods, analyzed by the statistical test method T, showed statistical significance in the water contamination in these collection periods in the two counties. The training and mobilization of the favored ones by the cisterns aremain aspects for better water quality, in order to minimize possible health risks and to ensure the 
correct functioning of these systems.

Keywords: RainWater; Microbiological Control; Coliforms; SEMLARID.

\section{MANEJO, ASPECTOS SANITARIOS Y CALIDAD DEL AGUA DE CISTERNAS EN COMUNIDADES DEL SEMIÁRIDO SERGIPANO}

RESUMEn - En regiones semiáridas de Brasil las tecnologías de captación de agua de lluvia auxilian en la provisión para consumo humano de varias familias, principalmente en los meses de estiaje. Para conocer esta realidad, la investigación fue desarrollada en comunidades rurales de los municipios de Simão Dias y Tobias Barreto, en Sergipe, con el objetivo de evaluar las formas de manejo y calidad del agua almacenada en cisternas domiciliares. La metodología adoptada fue del tipo cualitativa y exploratoria, desarrollada con la aplicación de 44 formularios para el diagnóstico socioambiental de las familias y recolecciónde 44 muestras de agua almacenada en las cisternas para análisis microbiológico en laboratorio. Los resultados de las muestras de agua revelaron contaminación microbiológica por Coliformes totales en todas las cisternas de ambos municipios y por Escherichia coli en el 100\% de los domicilios de Tobias Barreto y el 75\% de los de Simão Dias. El comprometimiento sanitario del agua posiblemente está relacionado a las deficiencias en la manutención y conservación del sistema de captación y almacenamiento de agua como tejados, canaletas, ductos y cisterna; y al manejo de los usuarios en la retirada del agua de las cisternas, en el cual predomina el uso de cubos presos en cuerdas. Las medias de Coliformes Totales y E. coli en los períodos lluvioso y seco, analizadas por el método estadístico test T, mostraron significancia estadística en la contaminación del agua en los referidos períodos de recolecciónen los dos municipios. La capacitación y movilización de los beneficiarios de las cisternas son aspectos centrales para mejor calidad del agua, para minimizar posibles riesgos parala salud y garantizar correcto funcionamiento de estos sistemas.

Palabras-Clave: Agua de Lluvia; Control Microbiológico; Coliformes; Semlárido.

\section{INTRODUÇÃO}

As regiões semiáridas brasileiras são marcadas pela escassez de água. A irregularidade pluviométrica, alta evapotranspiração e os longos períodos de estiagens são características naturais destas áreas e explicam parte desta problemática. Para permitir a convivência das famílias com esta realidade, o aproveitamento da água da chuva é uma alternativa viável, já que este recurso natural existe, mas por ser distribuído de modo desigual precisa de armazenamento para atender as demandas dos moradores principalmente nos meses de estiagem.

Para ampliar a prática de acúmulo de água de chuva e atender necessidades básicas como beber e cozinhar da população que vive no semiárido, políticas públicas de construção de cisternas rurais vêm se ampliando. O P1MC, financiado pelo governo federal e em parceria com entidades civis, tem como meta construir 1 milhão de cisternas nas regiões semiáridas e garantir água de qualidade para o consumo de famílias rurais.

Em sistemas de abastecimento de água desta natureza, a qualidade da água e os riscos à saúde humana decorrentes de seu consumo estão diretamente relacionados com os materiais utilizados na construção das estruturas, com o desenho físico e com as práticas de operação e manutenção utilizadas pelos usuários. O controle das características estruturais dos sistemas de captação de águas pluviais, assim como a mobilização e capacitação dos beneficiários, são aspectos centrais na busca por minimizar possíveis riscos para a saúde e garantir o correto funcionamento dos mesmos (Gomes et al. 2014).

Nas áreas rurais semiáridas, a água da chuva normalmente não é contaminada, entretanto o contato desta com as superfícies de captação das cisternas (telhados), o transporte pelas calhas e dutos e o manejo por parte dos moradores, podem elevar as possibilidades de contaminação. Quando a cisterna acumula somente água de 
chuva e tem manejo cuidadoso, incluindo descarte do primeiro milímetro de cada chuva e o uso de bomba para retirada da água, a qualidade é muito melhor e pode atender o padrão de potabilidade. A segurança sanitária de sistemas de captação de água de chuva em cisternas depende da educação dos usuários e do manejo seguro, mas, também, de um projeto adequado, inspeção regular e manutenção do sistema (Andrade Neto 2013).

A contaminação microbiológica pode comprometer a qualidade da água da chuva e causar efeitos deletérios à saúde dos usuários das cisternas, como as doenças de veiculação hídrica. De acordo com a resolução no 2.914 de dezembro de 2011, o Ministério da Saúde do Brasil recomenda investigar a presença de bactérias do tipo coliformes para definir o padrão microbiológico da qualidade da água, como importante medida para prevenção e saúde das famílias (Brasil 2011).

Tecnologias sociais de captação e armazenamento de água devem ser implantadas em conjunto com ações de educação ambiental, veículo de sensibilização e transformação, para estimular o fortalecimento e uso das barreiras sanitárias que preservem a qualidade do recurso. As ações educativas são ferramentas no processo de mudança de atitudes e desenvolvidas de forma contínua fomentam a preservação dos recursos naturais, mas devem respeitar e utilizar as diversidades de percepções, concepções e modos de apropriação da água dos habitantes das diferentes regiões (Silva 2014).

A valorização das barreiras sanitárias nas etapas de captação, armazenamento e manejo das águas pelas famílias é uma das estratégias da educação ambiental que garante água de boa qualidade e contribui para a eliminação de doenças de veiculação hídrica. A educação para a água não pode estar centrada apenas nos usos que fazem dela, mas na visão de que a água é um bem que pertence a um sistema maior, integrado, que é um ciclo dinâmico sujeito às interferências humanas (Bacci e Pataca 2008).

Considerando a importância da política de captação e armazenamento de água de chuva em comunidades rurais do semiárido, sobretudo por não possuírem sistema de abastecimento público de água, esta pesquisa pretende analisar as formas de captação, armazenamento e manejo, bem como a qualidade microbiológica da água acumulada em cisternas domiciliares de comunidades rurais dos municípios Sergipanos de Simão Dias e Tobias Barreto.

\section{Material e Métodos}

A área de estudo compreende comunidades rurais dos municípios de Simão Dias e Tobias Barreto (Figura 1), localizados no Território centro sul Sergipano, os quais apresentam extensão territorial de $564.702 \mathrm{~km}^{2} \mathrm{com}$ 38.702 habitantes e 1.021,30 km² com 48.040 habitantes respectivamente (IBGE 2010). Esta região caracterizase como semiárida, pelas condições climáticas com temperatura média anual que varia entre $20,3^{\circ} \mathrm{C}$ a $32,8^{\circ} \mathrm{C}$, eprecipitação pluviométrica anual inferior a $1100 \mathrm{~mm}$ decaindo para menos de $750 \mathrm{~mm}$, segundo informações fornecidas pelo SEMARH/SRH 2016.

A escolha destes municípios para avaliação das características de captação, armazenamento e manejo das cisternas localizadas em algumas de suas comunidades rurais, se justifica por sua representatividade na política social P1MC (programa 1 milhão de cisternas) executada pela Articulação do Semiárido (ASA), e pelo baixo índice de desenvolvimento humano (IDH) municipal, sendo IDH de Tobias Barreto 0,55 e Simão Dias 0,59 (IBGE 2010). Em Simão Dias existem 2408 cisternas construídas, que atendem 8528 pessoas, e Tobias Barreto dispõe de 2056 cisternas que beneficiam 7817 pessoas, ambos representando mais de 69\% das cisternas 
domiciliares construídas no território centro sul Sergipano (Brasil2015).

Figura 1 - Mapa do território Centro-Sul Sergipano.

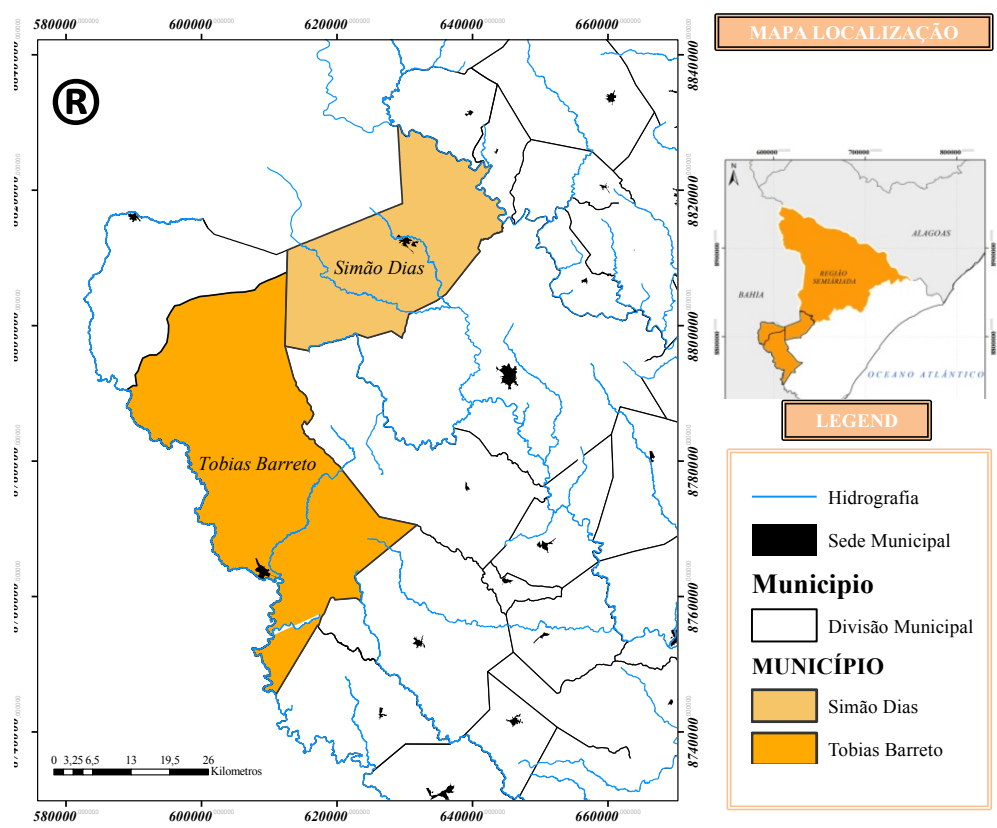

Fonte: SERGIPE, 2014.

A amostra foi definida de acordo com o número de cisternas construídas pela ASA naqueles municípios, representando $1 \%$ das cisternas instaladas em cada um deles, que correspondem a 20 domicílios em Tobias Barreto e 24 em Simão Dias. O critério de escolha para visita fundamenta-se na técnica "snowball", na qual o $1^{\circ}$ entrevistado indicará o próximo participante que também é beneficiário do sistema de captação e armazenamento de água e assim sucessivamente (Bailey 1994).

A metodologia adotada foi do tipo qualitativa e exploratória, desenvolvida com a aplicação de 44 formulários para o diagnóstico socioambiental das famílias e coleta de 44 amostras de água armazenada nas cisternas para análise microbiológica em laboratório. A opção por esse método de análise de dados deve-se ao fato do mesmo permitir a observação, descrição e análise de um fenômeno, bem como explorar suas dimensões, o modo como se manifesta e como os componentes estão correlacionados.

Os formulários da pesquisa socioambiental, submetidos ao Comitê de Ética e Pesquisa do Instituto Federal de Sergipe, foram aplicados aos chefes das residências indicadas, e que possuíam cisternas domiciliares, para conhecimento das características de captação, armazenamento e manejo destes sistemas. As comunidades rurais visitadas no município de Simão Dias foram Apertado de Pedra (4), Areal (3), Aroeira (3), Paracatu (4) e Sítio Alto (10) e no município de Tobias Barreto Campestre do Abreu (8), Barriga (2), Jacaré (5) e Assentamento Novo Marimbondo (5).

Os parâmetros microbiológicos analisados de acordo com as técnicas da APHA 2012, coliformes totais (ME-LPA-01) e Escherichia coli (ME-LPA-06), definiram a metodologia quantitativa para análise da qualidade da água. Para esta avaliação foram coletadas 44 amostras de água, das quais 20 no mês de setembro de 2015 (período chuvoso), sendo 10 em cada município. E no mês de março de 2016 (período seco), foram feitas mais 10 coletas em Tobias Barreto e 14 em Simão Dias. 
A retirada de água da cisterna, no momento da coleta, foi feita pelo usuário como de costume, com balde ou bomba manual, a fim de reproduzir as mesmas condições de manejo. Os recipientes para as amostras, autoclavados e etiquetados pelo laboratório, foram preenchidos com a água das cisternas e acondicionados adequadamente sob refrigeração para entrega no Instituto de Tecnologia e Pesquisa (ITP) na Universidade Tiradentes em Aracaju/SE no mesmo dia da coleta para preservar as características do material.

Sobre os resultados microbiológicos das amostras de água foi realizado o teste estatístico T de Student, com nível de confiança de 95\%, para comparar as médias quantitativas das coletas nos períodos chuvoso e seco, das quais se desconhecia as respectivas variâncias, e determinar se há diferença significante de contaminação na água da cisterna com a variação sazonal (Ayres 2012).

Os dados microbiológicos de qualidade da água foram representados utilizando os diagramas do tipo BoxPlot. Esta metodologia possibilita a visualização das variâncias dos parâmetros em análise e suas influências ambientais através da representação dos valores médios e das assimetrias da distribuição ocorridas nos diversos pontos de coleta (Ramos Júniore Cruz, 2012; Rodrigues et al. 2014; Thebaldi et al. 2011).

\section{RESUltados E Discussão}

A importância do programa de cisternas para o semiárido Sergipano reside na possibilidade de armazenamento e acesso à água de qualidade, já que nas comunidades rurais visitadas em Tobias Barreto e Simão Dias não há abastecimento público de água, e antes da implantação de cisternas a principal fonte de água das famílias pesquisadas era barragens e açudes (Figura 2A).O consumo de água da baixa qualidade ocorre em outras comunidades rurais do semiárido, como na Tiquara (BA), na qual antes da aquisição das cisternas os moradores usavam água proveniente de poços artesianos (67\%) com características salobras, além de barreiros $(19 \%)$, açudes $(5 \%)$, carros-pipa (2\%) e outras fontes $(7 \%)$ (Neto et al. 2013).

O aproveitamento da água da chuva pelas comunidades de Sergipe representa um consumo de água de melhor qualidade, contudo foi constatado que a água armazenada nas cisternas analisadas não atende as demandas de todas as famílias durante o período de estiagem. Nestes casos, o uso das fontes de água anteriores às cisternas e o uso de carros-pipa são as formas de sobrevivência destas populações.

Em Simão Dias os moradores recorreram a outras fontes de água quando a da cisterna é insuficiente, sendo os tipos usados chafariz (42\%), carro-pipa (25\%) e poço (8\%). Para as famílias de Tobias Barreto, as outras fontes são carro-pipa (30\%), poço (25\%) e barragem/açude (10\%). Entretanto para 35\% das cisternas de Tobias Barreto e 25\% das de Simão Dias a água de chuva nunca acaba e permite que os moradores consumam de água de melhor qualidade, mesmo no período de estiagem, e não precisem buscar água distante de casa como a maioria dos usuários (Figura 2B).

Com relação ao aspecto da quantidade de água armazenada e demanda, alguns estudiosos acreditam que nenhuma iniciativa isolada é capaz de atender plenamente às necessidades de água para consumo doméstico e produtivo das famílias rurais (Araújo et al. 2010). Concordando com esta análise, o estudo de Gomes e Heller (2016) verificou que a redução da dependência em relação aos carros-pipa ocorreu em comunidades que apresentavam outras das fontes de água, além das cisternas implantadas pelo P1MC. Independente da questão da quantidade de água necessária, existea preocupaçãocom de qualidade da água consumida proveniente do abastecimento com carros-pipa, quefoiexpressaem vários estudos (Brito et al. 2005; Silva et al. 2011). 
Figura 2 - A) Fontes de água usadas pela população antes da construção das cisternas e B) água usadas pela população quando água da cisterna é insuficiente.
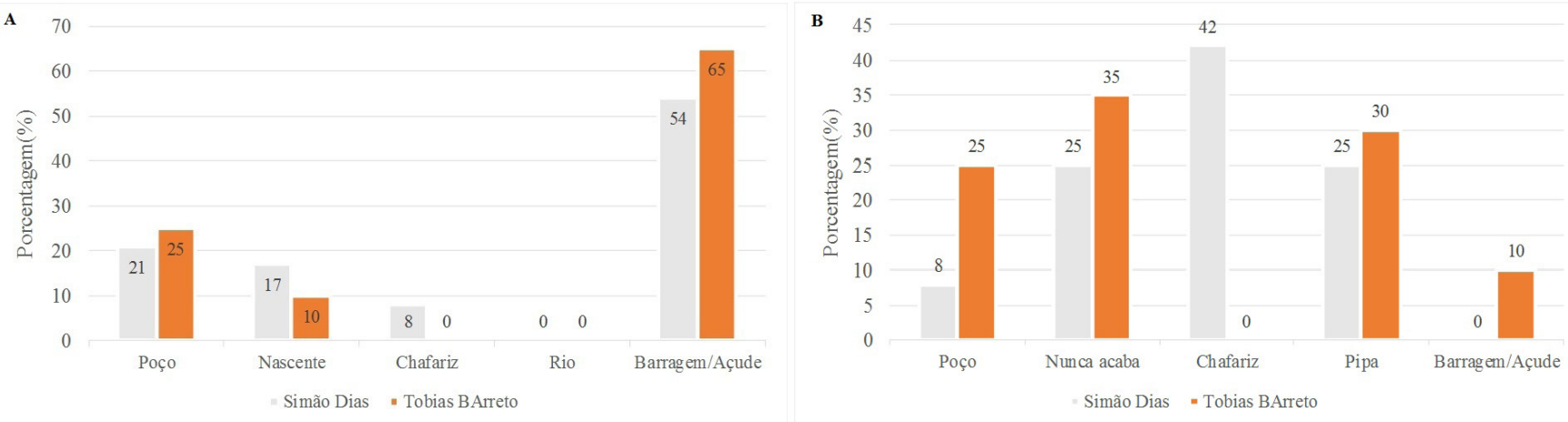

O consumo racional da água das cisternas é fundamental, pois estas tecnologias sociais armazenam 16.000 litros para atender famílias com até 5 integrantes para necessidades básicas como beber, cozinhar, lavar as mãos e utensílios domésticos de uso imediato (Brasil 2015). A maioria das comunidades estudadas apresentou 3 a 4 moradores por domicílio (Figura 3A) e expressa a situação da região nordeste, onde a maioria dos domicílios também tem este número de moradores segundo censo 2010 do IBGE.

A análise do gráfico da Figura 3demonstra uma mudança no tamanho das famílias, já que em Simão Dias 25\% delas são constituídas por 5 a 7 moradores, o que significa maior tendência de consumo de água neste município e explica por que um maior número dos seus moradores deste município buscaram por outras fontes de água (75\%) em relação aos de Tobias Barreto, cujo percentual é de 65\%.

A sustentabilidade do programa de cisternas domiciliares também pode ser comprometida pelos múltiplos usos da água da chuva. Beber e cozinhar representa 70\% do consumo em Tobias Barreto e 58\% em Simão Dias, contudo outras formas de uso da água também foram verificadas nos dois municípios, sendo banho a mais significante e que corresponde a 20\% em Simão Dias e 12\% em Tobias Barreto, além de limpeza e lavagem de roupa (Figura 3B).

Figura 3 - A) Número de moradores por domicílio que utilizam água da cisterna B) usos múltiplos para água da cisterna.
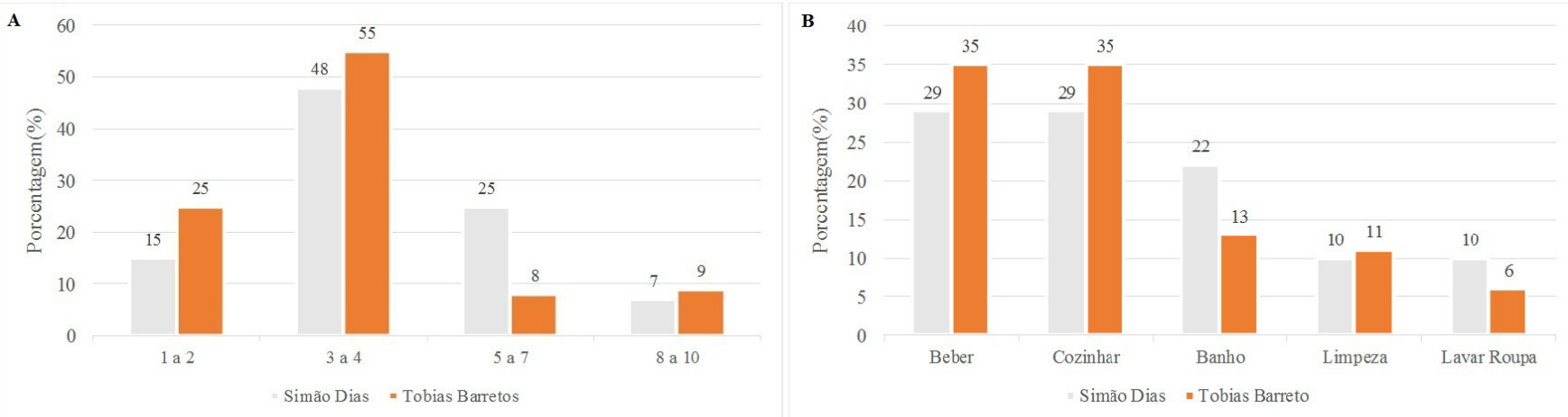

Tavares (2009) relatou que a falta de manutenção e conservação dos sistemas de captação e armazenamento, bem como e o manejo inadequado da água da chuva podem comprometer a boa qualidade deste tipo de água na zona rural e contribuir para a contaminação da água da cisterna promovendo riscos para saúde da população. As cisternas pesquisadas nas comunidades de Simão Dias e Tobias Barreto apresentaram fatores que podem comprometer a qualidade da água da chuva captada e armazenada, como: problemas estruturais envolvendo 
tubulações mal adaptadas ou sujas, calhas deformadas e incompatíveis com os tubos condutores, tampas quebradas ou empenadas, além de variações na frequência de limpeza do reservatório e desvio manual das primeiras águas da chuva, já que inexistem dispositivos de desvio automático (Figura 4).

Figura 4 - Problemas estruturais em calhas e tubos condutores.
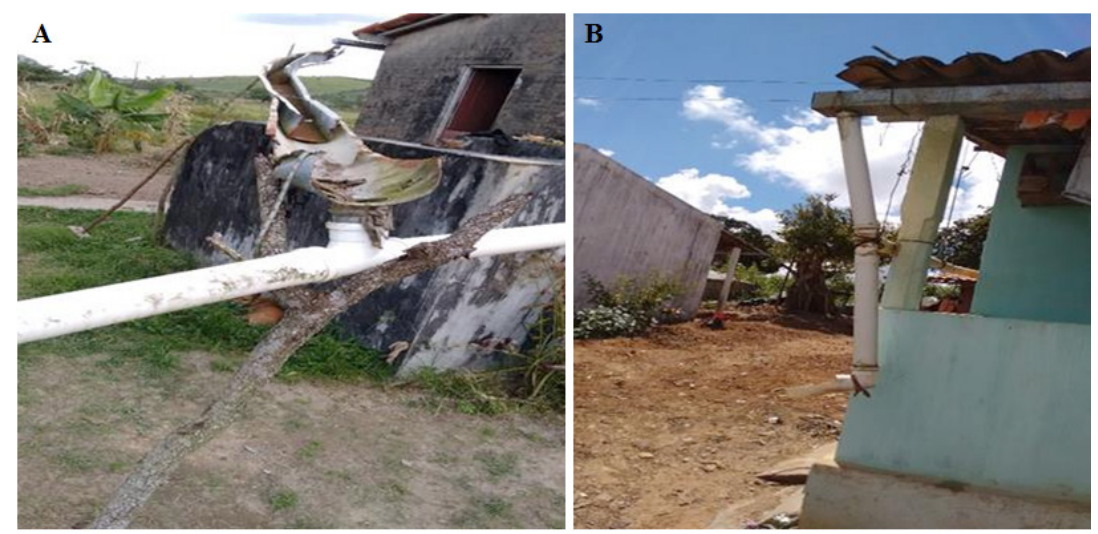

A captação da água da chuva em Simão Dias através de telhados apresentou problemas nas tubulações em 60\% dos domicílios pesquisados, além de má conservação das calhas de direcionamento da água (30\%) e 10\% de tampas das cisternas quebradas (Figura 5A). Quanto ao procedimento de desvio manual das primeiras águas de chuva, que visa promover a limpeza do telhado e condutores horizontais e verticais para evitar que as sujeiras acumuladas ao longo do período de estiagem sejam levadas para a cisterna, 62,5\% dos domicílios não efetuam este serviço, o que pode contaminar a água captada pelo carreamento de poeiras acumuladas. Com relação à limpeza das cisternas, tem-se: $54 \%$ são lavadas 1vez/ano, $42 \%$ das famílias fazem a lavagem 1 vez a cada 2 anos e $4 \%$ após 3 anos.

Como o telhado, as calhas e as tubulações funcionam não só como estruturas físicas de captação e armazenamento da água da chuva, mas também como barreiras sanitárias, o manuseio de forma adequada pode minimizar a contaminação microbiana da água da chuva armazenada na cisterna (Xavier et al. 2011).

Para as comunidades rurais visitadas em Tobias Barreto, ocorreram problemas na estrutura de 50\% das tubulações, 25\% das calhas e 25\% das tampas das cisternas (Figura 5A). O desvio manual das primeiras águas é realizado por $95 \%$ dos moradores e representa aspecto bastante positivo para melhor qualidade da água consumida. A limpeza anual da cisterna ocorre em $60 \%$ dos domićlios, enquanto $25 \%$ nunca fez a higiene, $10 \%$ faz a cada 4 anos e 5\% após 3 anos de uso (Figura 5B).

Cisternas avaliadas no semiárido baiano apresentaram comportamento semelhante ao de Tobias Barreto/ SE com relação ao cuidado da limpeza das áreas de captação no início no período chuvoso, emostraram que $88,8 \%$ das famílias da zona rural de Serrinha/BA desviam as primeiras águas da chuva e contribuem para garantir a qualidade da água (Santos 2008).

A estrutura da cisterna é um ambiente vulnerável à contaminação, devendo ser mantida íntegra, com tampa fechada, interior lavado a cada período de estiagem e ter o sistema de bombeamento manual para evitar contato com a água armazenada e preservar sua qualidade. Entretanto, o hábito de retirar água através de balde significa risco de contaminação pela abertura da cisterna e introdução deste recipiente, que se apoiado no chão pode entrar em contato com fezes de animal de sangue quente e tornar-se veículo de transporte de microrganismos para água armazenada. 
Figura 5 - A) Problemas estruturais e desvio manual das primeiras águas da chuva e B) frequência de limpeza da cisterna.
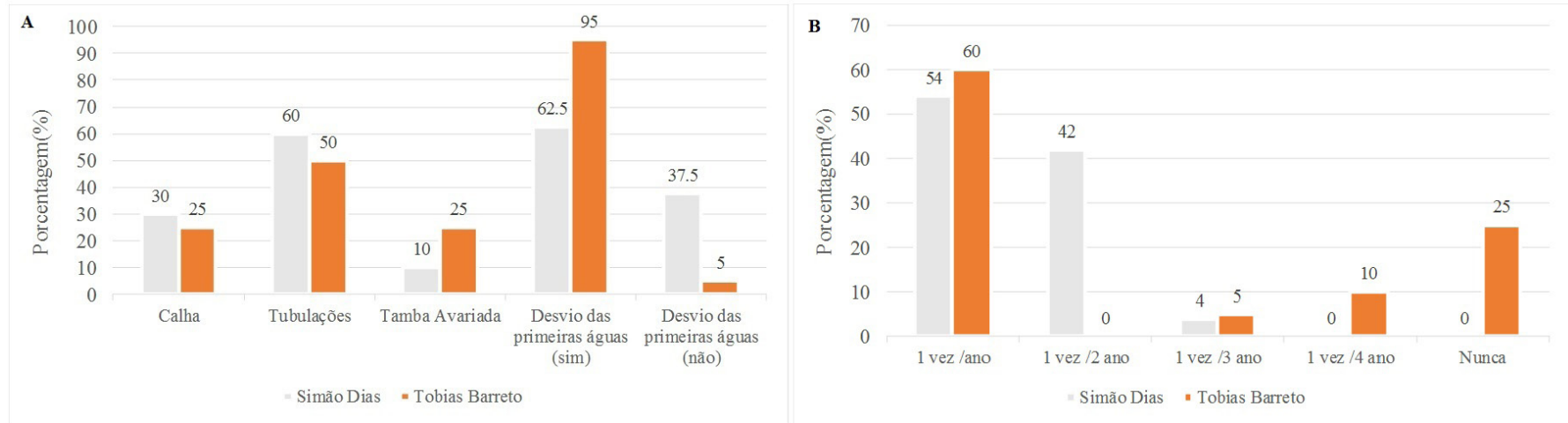

Nas comunidades pesquisadas, a retirada da água das cisternas ocorre principalmente com baldes. Nos domicílios de Tobias Barreto, 100\% dos moradores usam o balde para acessar a água, mas em Simão Dias $81,5 \%$ das residências recorrem a este método e as 18,5\% restantes, usam a bomba manual. Este equipamento vem instalado na cisterna e representa a forma mais recomendada para preservar a qualidade da água, mas os moradores alegam dificuldade de manuseio e quebra do mesmo como justificativa para utilizar o balde (Figura 6).

Figura 6 - Balde usado para retirar água de cisterna em comunidade de Sergipe.

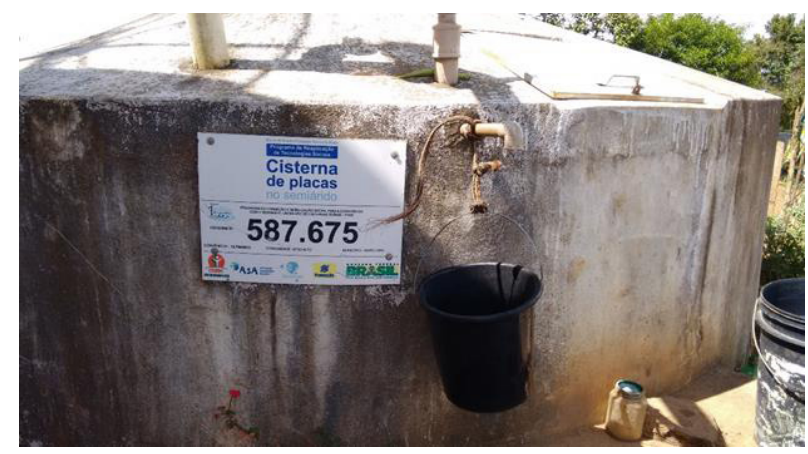

Como a contaminação microbiológica é o principal fator de degradação das águas de chuva, as concentrações microbiológicas em cisternas devem ser monitoradas. Os padrões de potabilidade da água, segundo a portaria 2.914/2011 do MS, consideram que os coliformes totais e os coliformes termotolerantes do tipo E. coli devem estar ausentes na água destinada ao consumo humano.

As análises microbiológicas nos dois municípios revelaram que a água, de chuva e mista, em todas as cisternas está imprópria para o consumo humano por causa da presença de coliformes totais, revelando deficiência na limpeza do sistema de captação e armazenamento das cisternas e ou baixa qualidade da água de carro-pipa (Figura 7A).

Em Simão Dias, os coliformes totais apresentaram valores de $3 \mathrm{NMP} / 100 \mathrm{~mL}$ a $920 \mathrm{NMP} / 100 \mathrm{~mL}$, enquanto Tobias Barreto teve a contaminação variando de $6 \mathrm{NMP} / 100 \mathrm{~mL}$ a 390 NMP/100mL (Figura 7). A dispersão dos valores de contaminação em Simão Dias é mais acentuada por causa da baixa adesão dos moradores no desvio das primeiras águas de chuva para limpeza do sistema. Na pesquisa socioambiental, apenas 37,5\% dos moradores disseram fazer este procedimento no início do período chuvoso, fundamental para assegurar melhor qualidade da água.

Para os coliformes do tipo E. coli, as análises da água no semiárido Sergipano tiveram valores de até 360 
UFC/100mL tornando a água inadequada para ingestão sem prévia descontaminação. Nas comunidades de Tobias Barreto, 100\% das amostras estavam contaminadas, enquanto em Simão Dias, foram 75\% de resultados insatisfatórios já que $25 \%$ dos valores foram nulos, como demonstra o valor mínimo e o 1o. quartil do gráfico box-plot (Figura 7A).

Figura 7 - Valores de A) coliformes totais e de B) Escherichia coli.
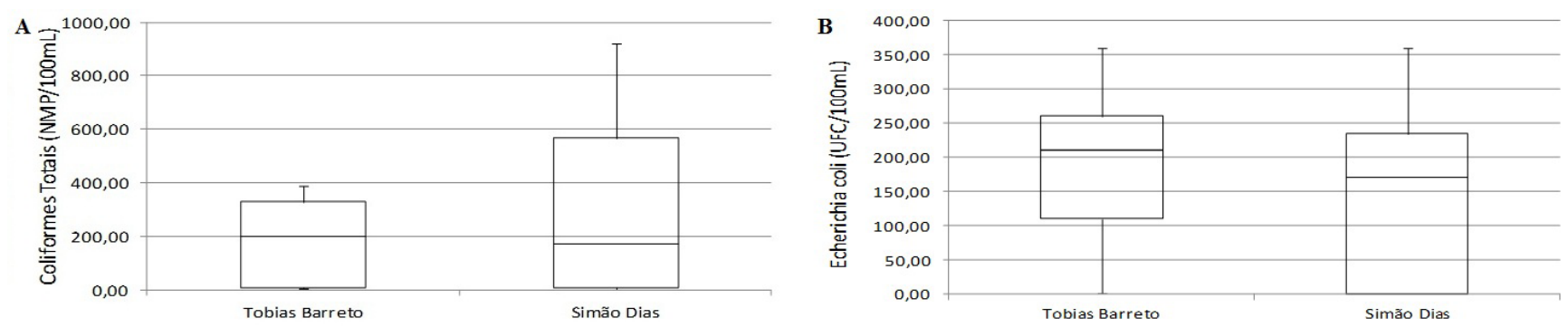

A presença de E. coli nas cisternas indica contaminação fecal recente e pode estar relacionada com o manejo dos usuários na retirada da água armazenada, realizada com baldes. Esta condição representa o comportamento adotado pelos usuários de Tobias Barreto e o nível de contaminação de 0,8 a 360 UFC/100ml encontrado. Em contrapartida, Simão Dias por ter 18,5\% dos domicílios usando bomba manual, tem melhor qualidade de água (Figura 7B).

Para verificar o comportamento dos níveis de contaminação microbiológica nas águas das cisternas, nos períodos chuvoso e seco, foi realizado o teste estatístico T-Student. Com este teste de hipóteses calcula-se o valor de T e T crítico a fim de analisar se as médias microbiológicas são iguais (hipótese nula) ou diferentes (hipótese não nula) nos distintos períodos de análise. O número de coletas analisados foram $20 \mathrm{em}$ Tobias Barreto (10 período chuvoso e 10 período seco) e 24 amostras em Simão Dias (10 período chuvoso e 14 período seco).

Os resultados do $\mathrm{T}$ crítico foram superiores ao $\mathrm{T}$ calculado para coliformes totais e E. coli nos dois períodos sazonais, significando a rejeição da hipótese nula, ou seja, as médias de contaminação são diferentes nos períodos chuvoso e seco. A análise da qualidade da água nesta amostra apresentou maior contaminação microbiológica no período chuvoso e representa riscos à saúde dos usuários neste período pelo maior consumo de água da cisterna já que no período seco ocorre uso de outra fontes de água (Tabelas 1 e 2).

Tabela 1 - Teste T para Coliformes Totais (NMP/100mL) nos períodos chuvoso e seco (TB - Tobias Barreto e SD - Simão Dias).

\begin{tabular}{lcccccc}
\hline Grupo Coliforme & $\mathrm{N}$ & Média & $\begin{array}{c}\text { Desvio } \\
\text { padrão }\end{array}$ & $\mathrm{T}$ & $\begin{array}{c}\text { DF } \\
\text { (T crítico) }\end{array}$ & $\begin{array}{c}\text { Significância } \\
\text { (2 extremidades) }\end{array}$ \\
\hline Período chuvoso & 20 & 1081,000 & 1243,559 & 2,178 & 42 & 0,035 \\
$\begin{array}{l}\text { (10 TB e 10 SD) } \\
\text { Período seco }\end{array}$ & & & & & & \\
$(10$ TB e 14 SD) & 24 & 352,958 & 974,259 & 2,130 & 35,693 & 0,040 \\
\hline
\end{tabular}

Os valores médios de contaminação por Coliformes Totais no período chuvoso foram superiores ao seco possivelmente pela precária limpeza das áreas de captação no final de cada estiagem, causando maior 
carreamento de contaminantes para a cisterna. Já no período seco, no qual já houve repetidos episódios de chuvas que limpam os telhados e calhas, além da presença de água de outras fontes trazidas por carros-pipa, a contaminação por coliformes totais foi menor (Tabela 1).

O uso de baldes presos em cordas é a forma de manejo predominante para retirada da água das cisternas em ambos os municípios, e por isso a causa mais provável de contaminação da água por E. coli. Desse modo, no período chuvoso que a cisterna tem mais água, o consumo e uso de baldes aumentam. Na estiagem, o uso da cisterna é restrito a quantidade de água armazenada, que geralmente é menor, ou as pessoas precisam optar por outras fontes até que ocorra novo período chuvoso (Tabela 2).

Tabela 2 - Teste T para E. coli (NMP/100mL) nos períodos chuvoso e seco (TB - Tobias Barreto e SD - Simão Dias).

\begin{tabular}{|c|c|c|c|c|c|c|}
\hline Grupo E. Coli & $\mathrm{N}$ & Média & $\begin{array}{l}\text { Desvio } \\
\text { padrão }\end{array}$ & $\mathrm{T}$ & $\begin{array}{c}\mathrm{DF} \\
\text { (T crítico) } \\
\end{array}$ & $\begin{array}{c}\text { Significância } \\
\text { (2 extremidades) }\end{array}$ \\
\hline $\begin{array}{l}\text { Período chuvoso } \\
\text { (10 TB e } 10 \mathrm{SD})\end{array}$ & 20 & 215,3400 & 108,96652 & 5,935 & 42 & 0,000 \\
\hline $\begin{array}{l}\text { Período seco } \\
\text { (10 TB e } 14 \\
\text { SD) }\end{array}$ & 24 & 39,0417 & 88,15031 & 5,820 & 36,425 & 0,000 \\
\hline
\end{tabular}

Confirmada a contaminação microbiológica por coliformes totais e termotolerantes nas áreas de estudo, recomenda-se que os usuários devem fazer a descontaminação da água da cisterna com cloro antes do consumo para eliminar as bactérias, já que a filtração remove partículas. A pesquisa nos domićlios demonstrou que $75 \%$ dos entrevistados fazem o tratamento da água com práticas diversas, como cloração, filtração e coando, enquanto $25 \%$ disseram que não tratam a água da cisterna antes do consumo.

Dentre os tipos de tratamento para água da cisterna utilizados, verificou-se em Simão Dias que 38,5\% dos moradores usaram cloro, 36,9\% realizaram filtração e 23\% apenas coaram a água. Em Tobias Barreto, a cloração ocorreu em $40 \%$ dos casos, $36 \%$ retiraram as impurezas coando e $24 \%$ disseram apenas filtrar a água antes do consumo.

Finalmente durante a pesquisa de campo verificou-se uma prática cultural nas comunidades estudas, em que $75 \%$ das cisternas visitadas em Tobias Barreto e 66,7\% em Simão Dias apresentaram peixes no interior. O diagnóstico socioambiental destas famílias rurais de Sergipe revelou que os moradores criam peixes na cisterna por acreditarem que essas espécies se alimentam de microrganismos que possam vir a adentrar nos reservatórios.

Estudo realizado no semiárido baiano, no município de Filadélfia, identificou realidade semelhante, na qual a criação de peixes em cisterna, para 49\% das famílias tem como objetivo controlar larvas de mosquito (Menezes et al. 2013).

\section{CoNCLUSÕES}

O aproveitamento da água da chuva pelas comunidades de Sergipe representa um consumo de água de melhor qualidade já que as comunidades estudadas utilizavam como fontes de água barragens, açudes e poços.

Constatou-se que a água armazenada nas cisternas não atendeu as demandas de todas as famílias durante 
o período de estiagem. Nestes casos, o uso das fontes de água anteriores às cisternas e o uso de carros-pipa são as formas de sobrevivência destas populações.

A sustentabilidade do programa de cisternas domiciliares ficou comprometida em Simão Dias, no qual $25 \%$ dos domićlios são constituídos por 5 a 7 moradores e apenas 58\% da água armazenada é usada para beber e cozinhar, sendo o restante distribuído para banho, limpeza e lavagem de roupas, o que significa maior tendência de consumo de água neste município e a busca por fontes de água distintas da água da chuva.

Nas comunidades pesquisadas verificou-se que a retirada da água das cisternas ocorre com baldes em 100\% dos domićlios de Tobias Barreto e 81,5\% dos de Simão Dias, em substituição à bomba manual, elevando as chances de contaminação da água.

O diagnóstico socioambiental revelou que $75 \%$ das cisternas visitadas em Tobias Barreto e 66,7\% em Simão Dias apresentam peixes no interior.

As amostras de água analisadas em laboratório apresentaram contaminação microbiológica por coliformes totais nas cisternas de todas as comunidades, e por E. coli em 100\% dos domicílios de Tobias Barreto e 75\% para Simão Dias, sendo consideradas impróprias para o consumo humano segundo a portaria 2.914/2011 do ministério da saúde.

$\mathrm{O}$ teste $\mathrm{T}$ demonstrou que a contaminação microbiológica foi mais elevada no período chuvoso se comparada com o seco, nos dois municípios estudados. Com relação aos Coliformes Totais, possivelmente decorreu da precária limpeza das áreas de captação no final de cada estiagem, causando maior carreamento de contaminantes para a cisterna. E a causa mais provável de contaminação da água por E. coli envolve o manejo de retirada da água, que é predominantemente feito com baldes, e que se eleva no período chuvoso quando a cisterna tem mais água.

\section{REFERÊNCIAS}

American Public Health Association - APHA. 2012. Standard methods for the examination of water and wastewater. 23st ed. Washington, DC: APHA, AWWA, WEF. 1082p.

Andrade Neto CO. 2013.Aproveitamento Imediato da Água de Chuva.Revista Eletrônica de Gestão e Tecnologias Ambientais,1(1):073-086.

Araújo VM, Ribeiro EMR, Reis RP. 2010. Águas no rural do semiárido mineiro: uma análise das iniciativas para regularizar o abastecimento em Januária. Organizações Rurais \& Agroindustriais, 12(2):219-233.

Ayres M.2012. Elementos de Bioestatística 2.ed. Belém-PA.2012.

Bacci DC, Pataca EM. 2008. Educação para a água. Estudos Avançados. São Paulo - SP, 22(63).

Bailey K. 1994. Methods of social reserarch. 4ed. New York: The free pass, 1994. 588p.

Brasil. 2011. Portaria MS no 2914, de 12 de dezembro de 2011. Diário Oficial da União, Brasília, DF, Seção 1, p. 3946. Acessado em www.saude.mg.gov.br, 2016.

Brasil, Articulação do Semiárido Brasileiro - ASA. 2015. Disponível em http://www.asabrasil.org.br 
Brito TL, Anjos JB, Porto ER, Silva AS, Souza MA, Xenofontes GHS. 2005. Qualidade físico-química e bacteriológica das águas de cisternas no município de Ouricuri-PE. In Simpósio de Captação e Manejo de água de chuva para sustentabilidade de áreas rurais e urbanas- tecnologias e construção da cidadania. Teresina - PI. Anais... Petrolina-PE: ABCMAC.

Gomes UAF, Doménech L, PenaJL, Heller L,Palmier LR. 2014.A Captação de Água de Chuva no Brasil: Novos aportes apartir de um olhar internacional.RBRH - Revista Brasileira de Recursos Hídricos.19(1):7-16.

Gomes UAF, Heller L. 2016. Acesso à água proporcionado pelo Programa de Formação e Mobilização Social para Convivência com o Semiárido: Um Milhão de Cisternas Rurais: combate à seca ou ruptura da vulnerabilidade? Eng Sanit Ambient. 21(3):623-633.

IBGE - Instituto Brasileiro de Geografia e Estatística. 2010. Censo Demográfico. Acessado em http://www. sidra.ibge.gov.br/bda/popul/.

Menezes GFF, Santos DB, Batista RO, Azevedo DO. 2013. Indicadores de qualidade, manejo e uso da água pluvial armazenada em cisternas do semiárido baiano. Revista Agrarian. 6(22):1984-2538.

Neto MS, Santos DB, Medeiros SS, Azevedo CAV, Júnior GG. 2013. Percepção, Manejo e uso da água das cisternas em comunidade do semiárido baiano. Associação Brasileira de Educação Agrícola Superior ABEAS - 28(1):56-62.

Ramos Júnior ABS, Cruz MJM. 2012. Variabilidade Espaço-Temporal de Parâmetro Físico-Químico e Metais Pesados no Rio São Paulo, Município de candeias, Bahia. Revista Geociências, 31(4):622-637.

Rodrigues ERD, Holanda IBB, Carvalho DP, Bernadi JVE,Manzatto AG, Bastos WB. 2014. Distribuição espacial da qualidade da água subterrânea na área urbana da cidade de Porto Velho, Rondônia. Revista ScientiaAmazonia, 3(3):97-105.

Santos MAF. 2008. Qualidade da Água de Chuva Armazenada em Cisternas Rurais e as Modificações Decorrentes do Manuseio na Região de Serrinha-BA. 71f. Dissertação (Mestrado em Engenharia Civil e Ambiental) Universidade Estadual de Feira de Santana, Feira de Santana.

SEMARH/SRH. 2016. Secretaria do Meio Ambiente e Recursos Humanos. Acessado em abril/2016. (http://www.semarh.se.gov.br/meteorologia/modules/tinyd0/index.php?id=45).

Silva NMD. 2014. Qualidade Microbiológica das Águas de chuva em cisternas da área rural do município de Inhambupe, no semiárido baiano e seus fatores intervenientes. Revista Eletrônica de Gestão e Tecnologias Ambientais 2(1): 172-187.

Tavares, AC. 2009. Aspectos físicos, químicos e microbiológicos da água armazenada em cisternas de comunidades rurais do semiárido Paraibano. Dissertação de mestrado. Prodema/ PB.

Thebaldi MS, SandriS, Felisberto AB, Rocha MS, Neto SA. 2011. Qualidade da água de um córrego sob influência de efluente tratado de abate bovino, Revista Brasileira de Engenharia Agrícola e Ambiental15(3):302-309. 
Xavier RP, Siqueira LP, Vital FAC, Rocha FJS, Irmão JI, Calazans GMT.2011. Microbiological quality of drinking Rainwater in the inland region of Pajeú, Pernambuco, northeast Brasil.Rev. Inst. Med. Trop. São Paulo. 53(3):121-124. 